Names, Vol. 38, No. 4 (December 1990)

\title{
Special Reports
}

Several meetings of importance to ANS took place this summer and early fall. Following are brief reports of three of these.

\section{$* * * * * * * *$ \\ ICOS Helsinki}

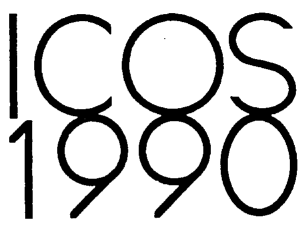

HELSIN KI

The XVIIth International Congress of Onomastic Sciences was held in Helsinki, Finland, during the week of August 13-18, 1990. The main theme of the program was Name Systems. There were 220 participants, all but 30 of them actively participating in the meeting. The languages of the sessions were English, French, German, and Russian. There were five plenary session speakers and 134 regular session papers. The interest of the audience was attested by the 500 questions and/or comments which followed presentations. Participants agreed that the quality of the papers was excellent.

The International Committee on Onomastic Sciences also met in two separate sessions on Tuesday and Thursday, with 34 members present. Nineteen new members were named, as well as four new honorary members. Prof. W. F. H. Nicolaisen was named the new Secretary General of ICOS. As its first work, the Committee voted to accept the revised statutes.

An important function of the Committee was to designate the locale and time of the next meeting. Prof. Dieter Kremer offered to host the next Congress at the University of Trier in 1993 during the Easter season in April. The Committee voted to accept his invitation. The general theme of the Congress will be Personal Names, broadly understood.

There was a proposal to restructure ICOS into an international society with a sponsored journal. Since this proposal is far-reaching, a subcommittee was established to study the matter, with Dr. Margaret Gelling as the subcommittee chair.

The participants did not spend all of their time in scholarly sessions. They also had the opportunity to become acquainted in more informal settings. There were official evening receptions by the City of Helsinki and the Swedish Literary Society on Monday and Tuesday respectively. On Wednesday participants could take a full-day or a half-day onomastic excursion, and on Friday evening there was a banquet with dancing. The congress closed on Saturday with a final session at 4 p.m.

Mary R. Miller

University of Maryland, College Park 


\section{Conference Reports}

\section{Western States Geographic Names Council Meeting}

Just as Native Americans have endured in America, so have issues surrounding collecting and preserving the placenames they've created.

For the second year, discussion of Native American names dominated the annual meeting of the Western States Geographic Names Conference (WSGNC), held September 5,1990 , in Washington, DC, in conjunction with the Centennial of the U. S. Board on Geographic Names (USBGN).

For some time now, the USBGN has been drafting a policy specifically for Native American names, as have their counterparts in Canada, and at the September 5 meeting representatives of geographic names authorities in eight western states reported on their experiences with Native American names. The issues discussed included:

-Difficulty of transcribing Native American names into Roman orthography. Grant Smith of Washington mentioned that the Native American name for the great waterfall in Spokane has been written as Stseqhwlkwe 'foaming water,' and Don Orth observed, "If you see a name on the map and can't pronounce it, you ignore it."

-Corruption of Native American names. Merle Wells of Idaho and several others mentioned that what often appear as Native American names on maps in fact are gross corruptions, transcribed by persons ignorant of the sounds and meanings of the Indian languages.

-Complexity of Native American languages and naming practices. In Oregon, many "Native American" names come from Chinook, a jargon language used by several tribes. In New Mexico, a feature may have names in as many as eight Indian languages. And within a single tribe, a feature may have several names, whose use depends on context, such as ceremonial oratory or everyday conversation.

-Native Americans' fear of bureaucracy. Numerous representatives mentioned that Native Americans typically show little interest in efforts to collect and preserve their names. This results from the religious nature of many names as well as from previous bad experiences with well-intentioned non-Native Americans. Efforts to have Native Americans involved in state names boards have not been very successful, and most states reported few proposals or issues involving Native American names.

-Jurisdiction. Many Native American groups regard their reservations as sovereign nations, and in Arizona a Navajo representative stated that they wanted to deal with the USBGN directly, with no involvement by state authorities. The WSGNC representatives, however, felt it was very important for them to be involved in all names issues in their states.

$-A$ growing sensitivity. Despite these obstacles to collecting and preserving Native American names, several persons said Native Americans increasingly are conscious of their heritage and are seeking greater recognition and validation of their cultures; geographic names will likely become an increasingly important part of this.

Because of this, Native American Names will continue as the theme of the 1991 WSGNC meeting, which will be held the second week of September in New Mexico. As the New Mexico representative, in charge of local arrangements I have promised to seek Native American representation at that meeting.

Bob Julyan 


\section{Centennial Celebration}

\section{U.S. Board on Geographic Names}

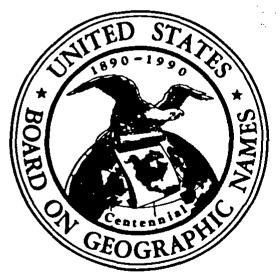

The U.S.Board on Geographical Names was created by an executive order signed by President Benjamin Harrison on September 4, 1890, and the Board and its friends commemorated this event with a celebration and conference at the Madison Building of the Library of Congress on September 6-8, 1990. Main organizer was BGN Chairman Ralph Ehrenberg, Assistant Chief of the Geography and Map Division of the Library of Congress, with considerable help from Richard Randall, BGN Executive Secretary, and Donald Orth, Executive Secretary for Domestic Names. Other members of the American Name Society were present and central to the program. Kelsie

Harder delivered the Keynote Address; Roger Payne, Lewis McArthur, and Grant Smith were among those on panels during the two-day symposium.

Partly because the Western States Geographical Names Council met the day before in the same location (see the report by Bob Julyan above), there was substantial representation from all across the country. There was also Foreign representation, from Canada and the United Kingdom.

The theme of the conference was The Board: Yesterday, Today, and Tomorrow. Appropriately, efforts and contributions of earlier Boards led off the Thursday session, with "Voices from the Past" including those of Lester Dingman, Theodore Liard, and Walter Ristow, among others. Meredith Burrill, BGN Executive Secretary Emeritus, spoke on "The Wonderful World of Geographic Names: Things Learned and Things Yet to be Learned." And Rupert Southard brought the day to a close with his usual witty insights. Friday's sessions focussed on the present and the future, with panels on how the Board Works with Foreign and US Agencies, Names and Automated Data Processing, What Federal Agencies Require of the Board, What State, Professional, Commercial, and Institutional Organizations Require of the Board, and a Discussion that brought these topics together.

But all was not business. A reception on Thursday night provided toponymic foods (Maryland crab cakes, Peking duck, etc.,), good wine, and good fellowship, all as part of the opening of the entertaining and informative exhibition, A World of Names, sponsored by The Library of Congress. On Saturday, two bus loads of participants, led by Martha Orth and Jon Campbell, travelled up the Potomac Valley to Harpers Ferry, stopping along the way to look at various sites of scenic and toponymic interest. The weather was perfect, the scenery spectacular, and the company ideal.

The centennial celebration for the Board on Geographic Names was a grand occasion. It's too bad we have to wait another hundred years to do it again.

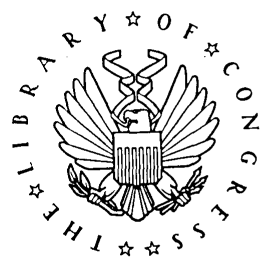

Thomas J. Gasque

University of South Dakota, Vermillion 


\section{Conference Reports}

\section{Placename Survey of the United States \\ Its First Steps in the Standardization of Data Fields}

It has not yet been reported in Names that The Placename Survey of the United States (PLANSUS) - a commission created by the American Name Society - reconstituted itself in April of 1988 and has since been working hard to organize the systematic study of placenames in this country. Bill Nicolaisen chaired the commission from April 1988 until November 1989 before going on leave to Denmark and Scotland and will, we hope, rejoin the commission when he returns next summer. Other current members include Len Ashley, Jon Campbell, Lurline Coltharp, Wayne Finke, Tom Gasque, Kelsie Harder (Director), Sarah Jackson, Bob Julyan, Tom Kallsen, Lewis L. McArthur, Mary R. Miller, Don Orth, Roger Payne, Bob Rennick, Wilbur Zelinsky, and me.

Thus far our goals may be listed as follows - a list that may be added to as our work progresses:

1. To encourage scholars at the state level to pursue contracts for Phase II of GNIS.

2. To expand our "Mission Statement" in more detail.

3. To seek ways to aid and assess scholars seeking grants for toponymic research.

4. To pursue the publication of an annotated, perhaps automated bibliography.

5. To lend recognition to particular institutions as centers of toponymic research.

6. To develop standards of research and scholarship, stressing both the interdisciplinary and systematic nature of toponymic studies.

7. To develop, describe, and define appropriate fields of information that might be added to GNIS.

8. To pursue international dialog about all aspects of toponymic research, especially about formatting, possible classification, and the automated storage, sorting, and retrieval of information.

These goals are meant to be comprehensive in terms of pursuing placename studies nationwide. For example, at our 1989 meeting we identified two national centers for toponymic research: the Geography Library of the University of Alabama and the Lurline H. Coltharp Collection of Onomastics at the Library of the University of Texas at El Paso. In the following spring, correspondence was exchanged with the two institutions which states their intention to provide continuing support. Other centers may be identified wherever significant resources and interest can be developed. Also, a new annotated bibliography compiled by Kelsie Harder and Don Orth is now in the hands of a publisher, and Mary Rita Miller has identified a number of possible granting agencies and has compiled a list which will appear in the ANS Bulletin.

Most of our work, however, has focused on the standardization of basic toponymic information. Two major developments led to reconstituting the Commission: The Geographic Names Information System (GNIS) and advances in personal computer technology. Placename data is extensive, and computers now make the recording, sorting, and retrieval of that information more practical than ever. Also, the wide use of personal computers has changed fundamentally the way individuals can share information. For such reasons PLANSUS has given its primary attention to the need for standard data fields, their organization, and their dissemination to and use by as many people as possible.

Editor's note: Because the recent activity of the Placename Survey of the U.S. may have gone unnoticed by many members of ANS, I asked Grant Smith, chairman of the commission, for a summary. 
Our most important subcommittee since 1988 has been that of Classification and Formatting, chaired by Lewis L. McArthur.

In twice yearly meetings this subcommittee has addressed theoretical issues such as the advisability of pursuing a morphology or typology of names, but within the past year has focused on the simple need for data and its organization. In the spring of this year (1990), McArthur and I co-authored for presentation to the Canadian Society for the Study of Names a paper which detailed the range of information needed and offered tentative definitions for six types of reference (a system of classification like George Stewart's ${ }^{1}$ and many others). The total range of information was divided into four categories which parallel modern semantic theory:

Referent (Feature) Information (for which the Phase II data fields are a start): (1) Record Names, (2) Feature Class, (3) State and County Code, (4) Map/Chart Code (for recording purposes), (5) Coordinates, (6) Status (e.g., Federal, State, or unofficial), (7) Variants, (8) Administrative Responsibility (ownership), (9) Section, Range, Township (Public Land Survey System), (10) Bibliography (source), (11) Elevation, (12) Size, (13) History (a very brief statement regarding name origin and meaning).

Symbol Information: (1) The language from which a name is derived, (2) Indicators of generics and specifics, (3) Phonemic transcriptions (for dialect study), (4) Morphological parts (especially for Native American languages), with (5) A morphological gloss, and (6) A phrasal translation.

Namer Information: (1) Date(s), (2) responsibility, corporate or individual, (3) Name, (4) Title, (5) Language of the namer (perhaps a Frenchman or Englishman using a term borrowed from a Native American language), (6) Sex, (7) Age, (8) Nationality, (9) Status -i.e., governmental (local, regional, national, and international indicators should be included), owner, explorer, visitor, transient, contest winner, other community leader, (10) Primary commercial interest, profession, or employment.

Reference Categories (associations linked to the feature by the symbol): (1) Biographical - a name that is also a given name or a surname of an individual or the name of a group, (2) Physical - a name that denotes or describes a natural landscape characteristic, (3) Biological - a name that refers to any flora or fauna or subdivision thereof, (4) Activity - a name that refers to an activity either human or natural, (5) Coinage - a name that combines phonemes or letters without standard lexical meaning or that reflects errors in transmission, (6) Miscellaneous - a name that alludes to literature, etc., or that comes from any source not accounted for above, and (7) Not Determined -a name that has not been satisfactorily explained.

This list was refined and expanded with examples and additional narrative as part of a presentation at the International Congress of Onomastic Sciences in Helsinki, Finland, August 13-18, 1990, entitled "Plans for the 'Placename Survey of the United States," It should be available soon as part of the Proceedings.

McArthur has been energetic both as a leader of his subcommittee and in testing the classifications of "Reference" in his database of Oregon names. He uses an IBM personal computer with dBase IV software and has provided the subcommittee with test printouts at each meeting. Thus, the subcommittee has had a plethora of examples and has discussed numerous subdivisions within the categories listed here. However, the goal settled on by the subcommittee was to agree on a general or "first cut" level of categories and to leave further divisions to individual researchers or for subsequent discussion.

At a meeting of PLANSUS held conjointly with the Western States Council and the U.S. Board's Centennial Celebration in September 1990, the full commission voted by acclamation to adopt tentatively the six basic categories of the "Reference" field (the seventh category, "Not Determined," would be indicated by leaving the field blank) plus three other fields of data recommended by McArthur and his subcommittee. The three 


\section{Conference Reports}

other fields include (1) identification numbers (needed to distinguish different features with the same name), (2) dates of first usage, when known, and (3) whether the name is a "primary" name, a "transfer," or a "shift" (as defined by Stewart xxxi).

Approval of these four fields is an important step forward in the description of standard data fields. The reference categories are particularly difficult: the meaning of language is always dependent on context, and classification is an act of interpretation. Data about the "feature" named, the "symbol," and the "namer" help to clarify context and meaning, and these, and perhaps other, types of data and their arrangement (listing) in computer fields will be the next focus of attention for PLANSUS. The Commission has reduced the size of its subcommittee and hopes to select and define a basic set of data fields by the 1991 meeting of the Western States Geographic Names Council in New Mexico in September.

If readers have suggestions about the data fields as described here, especially additions, they should send them to me or to Roger Payne (Manager, GNIS, P.O.Box 3356, Reston, VA 22090), who will convene the new subcommittee. The next few months will be important and feedback may be crucial. If it is to continue its pursuit of a national survey, the commission must find a general consensus among researchers and government agencies on the basic types of information needed to serve widely differing geographies, cultural histories, and professional interests. Also, for each computer field it must decide the specific format in which the data should be stored - numeric or alphabetical abbreviations. Such formatting decisions will affect the "user friendliness," the speed of entering, sorting, and retrieving data, and how much data can be printed out on a single page.

Of course, selecting, defining, and describing the types of information to be included and settling on the formats are just the beginning of a much larger project, and that is the actual gathering of information. The GNIS data is limited in type, but at least ten years away from the completion of Phase II. The studies assumed by PLANSUS will at least triple the GNIS types of data. Much data is readily available, some even in machine readable form, but the task ahead seems longer than anyone would want to predict at this time. My personal hope is that if the data are broad enough, the definitions clear enough, and the format easily manipulable, government agencies, foundations, and potential users might fund some of the research.

PLANSUS will meet next in Chicago in December 1990, and I hope to report to you again in these pages in about a year.

Grant Smith

Eastern Washington University, Cheney

\section{Notes}

1. See his revised version in American Place-Names: $A$ Concise and Selective Dictionary for the Continental United States of America (New York: Oxford UP, 1970): xxviii-xxxii. There are, of course, many classification systems.

2. For these latter suggestions, I am indebted to Prof. Gary B. Palmer, an anthropologist at the University of Nevada - Las Vegas, who has compiled a study (not yet published) of Native American placenames used by the Coeur d'Alene Indians. See his review of "Ethnogeography with MICROSOFT FILE (MS FILE) Data," Social Science Microcomputer Review n.d.: 91-99. 